\title{
Caracterização de Passiflora mucronata Lam.: nova alternativa de maracujá ornamental ${ }^{(1)}$
}

\author{
LAURA MARIA MOLINA MELETTI(2); MARTA DIAS SOARES-SCOTT(2,3); LUÍS CARLOS BERNACCI(4); \\ VALDEMIR ALVARES(4); JOAQUIM ADELINO DE AZEVEDO FILHO(5)
}

\begin{abstract}
RESUMO
No Brasil, a família Passifloraceae possui ampla diversidade genética devido ao elevado número de espécies nativas, entretanto, o valor ornamental da família ainda é praticamente inexplorado. Passiflora mucronata Lam. é uma das espécies nativas que integram o Banco de Germoplasma de Maracujazeiros do Instituto Agronômico (IAC), que estão sendo caracterizadas para fins ornamentais, em condições de campo, objetivando sua utilização comercial. Foram avaliados desenvolvimento vegetativo, época de florescimento, período de antese, compatibilidade, viabilidade polínica, produção de frutos, comportamento germinativo e longevidade das sementes. As flores de P. mucronata são brancas, fosforescentes e têm antese noturna, atraindo mariposas e morcegos. A viabilidade polínica permaneceu elevada (75,8\%), desde a antese (18h00min h) até a manhã seguinte. A espécie mostrou-se autoincompatível. A polinização cruzada resultou em frutos ovoides, com 14,82g de peso médio, $4,59 \mathrm{~cm}$ de diâmetro longitudinal por $2,73 \mathrm{~cm}$ de diâmetro equatorial. A casca do fruto é delgada, amarelo-canária quando totalmente maduro. A polpa apresentou pouca suculência, sem aroma característico, mas sabor agradável. As sementes são achatadas, de coloração marrom-enegrecida, com dormência quando recém-colhidas, o que pode ser superado efetivamente com armazenamento em câmara fria e seca mais choque térmico, associados. A longevidade das sementes foi de cerca de um ano. Os acessos avaliados de P. mucronata evidenciaram se tratar de uma planta de vigor vegetativo intermediário, tolerante ao frio, com intenso florescimento, que se estende por um longo período do ano. Em função destas vantagens adicionais, pode ser utilizada como planta ornamental, uma alternativa dentro do grupo das trepadeiras indicadas para cercas vivas ou caramanchões.
\end{abstract}

Palavras-chave: maracujá, plantas ornamentais, trepadeira, Passifloraceae, cerca viva, caramanchão.

\section{ABSTRACT}

Characterization of Passiflora mucronata Lam., a new ornamental alternative

\begin{abstract}
In Brazil, the Passifloraceae family has an extensive genetic diversity due the high number of native species, however, the ornamental value of the family is still almost unexplored. Passiflora mucronata Lam is a native species that integrates the Germplasm Bank of Passion Flowers from Instituto Agronômico (IAC), being characterized as an ornamental, aiming to know its behavior in field conditions, contributing to commercial use. We evaluated the vegetative growth, flowering, anthesis period, compatibility, pollen viability, fruit production, germination behavior and seed longevity. Passiflora mucronata's flowers are white, phosphorescent and have nocturnal anthesis, attracting moths and bats. Pollen viability remained high (75.8\%), from anthesis (6:00 h P.M.) until the next morning. The species showed self-incompatible. Cross-pollination resulted in ovoid fruits, with $14.82 \mathrm{~g}$ mean weight, $4.59 \mathrm{~cm}$ in longitudinal diameter by $2.73 \mathrm{~cm}$ in equatorial diameter. The epicarp is thin, canary-yellow when fully ripe. The pulp showed little succulence without aroma, but has good flavor. The seeds are flat, blackish-brown color with dormancy when freshly harvested, which could be effectively overcome with cold storage and dry more thermal shock associated. The seeds longevity was about one year. The P. mucronata genotypes evaluated presents an intermediate vigor plant, cold tolerance with intense flowering production in the curtain area, almost continuously throughout of year. Due these additional benefits can be used as an ornamental plant, an alternative within the group of climbers set out for hedges or trellises.
\end{abstract}

Keywords: passion flower, ornamental plants, climber, Passifloraceae, hedge, trellises.

\section{INTRODUÇÃ̃O}

A família dos maracujás (Passifloraceae) tem distribuição original nos trópicos e regiões temperadas quentes, principalmente na América e África. No Brasil, são reconhecidos quatro gêneros - Ancistrothyrsus Harms, Dilkea Mast., Mitostemma Mast., Passiflora L. - e 135 espécies, sendo 129 da espécie Passiflora, das quais 83 exclusivas (endêmicas) do Brasil (Cervi et al., 2010).

O cultivo econômico do maracujá como fruteira tropical se iniciou na Austrália e no Havaí, com a utilização de espécies nativas do Brasil, principalmente Passiflora edulis
Sims.

Considerando a grande variabilidade genética das espécies, principalmente as da biodiversidade brasileira (BERNACCI et al., 2005), há um grande potencial para o cultivo ornamental, seja como soluções paisagísticas para áreas grandes e médias, seja como plantas de vaso que são usadas em varandas ou dentro de casa.

Passiflora mucronata Lam. é uma das espécies nativas presentes no Banco Ativo de Germoplasma (BAG) de Maracujazeiros do Instituto Agronômico (IAC) estudadas visando a identificar as mais promissoras para fins ornamentais. Nativa da Mata Atlântica, ocorre do litoral sul da

\footnotetext{
(1) Recebido para publicação em 10/12/2010 e aceito em 15/05/2011.

(1) Pesquisador Científico, IAC - Instituto Agronômico, APTA, Centro de Recursos Genéticos Vegetais, Fazenda Santa Elisa. Campinas, SP. CEP: 13.075-630.

(2) Autor para correspondência : scott@iac.sp.gov.br

(4)Assistente Técnico, Instituto Biológico-APTA, Centro Experimental Fazenda Mato Dentro, C. Postal 70, Campinas, SP. CEP: 13.001-970.

(5) Pesquisador Científico, APTA - Pólo Regional Leste Paulista, Caixa Postal 01, Monte Alegre do Sul, SP. CEP: 13.910-000.
} 
Bahia, onde também é conhecida como maracujá-pintado, até o litoral norte de São Paulo (BERNACCI et al., 2003). Suas sementes são consideradas vermífugas e das raízes se obtém um extrato de efeito calmante (INGLEZ-DE-SOUZA e MELETTI, 1997).

O conceito de planta ornamental é bastante relativo e particular ao observador, pois envolve sentimentos estéticos subjetivos. MELLO FILHO (1986) conceitua planta ornamental como aquela capaz de despertar estímulos derivados de suas características intrínsecas como coloração, textura, porte, forma, aspectos fenológicos, etc., ou extrínsecas, como o balanço ao vento, a sombra projetada ou a composição estrutural com a vizinhança.

Este trabalho visa à caracterização de genótipos da espécie $P$. mucronata L., presentes no BaG de Maracujazeiros do IAC. O conhecimento de suas características permite descrever seu comportamento e contribuir para futura utilização comercial, em curto prazo, de plantas selecionadas.

\section{MATERIAL E MÉTODOS}

Plantas de Passiflora mucronata de cinco acessos diferentes (São Paulo, Rio de Janeiro, EEMAS, Pólos e Ibiti), pertencentes ao BAG de Maracujazeiros do IAC, foram avaliadas e cruzadas entre si, em condições de campo, durante sete anos consecutivos (2004 a 2010), na área experimental do Polo Regional de Desenvolvimento Tecnológico dos Agronegócios do Leste Paulista, em Monte Alegre do

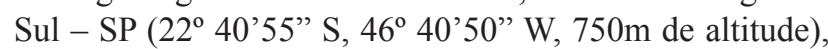
em área de solo Podzólico Vermelho-Amarelo. O clima regional apresenta temperatura média anual de $20,9^{\circ} \mathrm{C}$ e precipitação média anual de $1503 \mathrm{~mm}$ (período de 19611990 - ROLIM e SENTELHAS, 1999), sendo classificado como mesotérmico úmido sem estiagem - Cfa, no sistema de classificação de Köppen. Nos anos de estudo, a média das máximas foi de $27,13{ }^{\circ} \mathrm{C}$ e a das mínimas foi de 14,34 ${ }^{\circ} \mathrm{C}$ (CIIAGRO, 2010).

Os acessos São Paulo e Rio de Janeiro foram avaliados por todo o período, sendo que o primeiro esteve presente no BAG desde 1997, morrendo apenas em setembro de 2010. O acesso EEMAS passou a ser avaliado a partir de 2007, e os acessos Polos e Ibiti, a partir de 2009. A adubação de plantio e a de produção foram realizadas segundo recomendações de MELETTI e MAIA (1999), acrescidas de pulverizações com adubo foliar à base de $\mathrm{CaB}$ durante os meses de frutificação. As plantas foram conduzidas em espaldeira vertical até a altura de $2 \mathrm{~m}$ do solo, com espaçamento de $5 \mathrm{~m}$ entre linhas e $1,5 \mathrm{~m}$ entre plantas. A irrigação foi realizada com 50 L por planta, com auxílio de tanque. A partir de 2009, a irrigação passa a ser realizada com fita gotejadora, sempre que necessário, na base de $12 \mathrm{~mm}$ por semana.

As características fenológicas observadas foram: vigor vegetativo, medido pela velocidade de crescimento da planta até a altura do arame ( $2 \mathrm{~m}$ do solo); período de florescimento e frutificação ao longo do ano; período de antese no dia; autoincompatibilidade; viabilidade polínica; qualidade dos frutos; comportamento germinativo; e longevidade das sementes. As observações de campo foram feitas visualmente por meio de visitas mensais ao BAG. Nos Laboratórios de Qualidade de Frutos e de Citogenética do IAC, em Campinas, foram feitas as avaliações dos fru- tos e sementes e de viabilidade polínica, respectivamente.

O pegamento dos cruzamentos manuais foi avaliado após oito dias da polinização. O sucesso reprodutivo foi considerado quando os frutos apresentaram cavidade interna preenchida com polpa e sementes escuras, viáveis, potencialmente capazes de originar descendentes férteis.

Os cruzamentos controlados foram realizados manualmente entre plantas bastante produtivas (com mais de 15 frutos por metro linear de planta) e com amplo período de florescimento, ensacando-se as flores antes da antese, com sacos tipo pergaminho.

Para a análise da viabilidade polínica, foram empregadas a técnica de coloração de Alexander (1980), avaliando-se 300 grãos de pólen por flor, em 72 flores, coletadas em diferentes períodos do ano, e teste de germinação de grãos de pólen, utilizando-se pólen fresco de flores recémabertas, semeadas em lâmina de gota pendente em meio líquido, segundo técnica de Daulta e Chauhan (1987) e em meio semissólido, de ágar 2\% e sacarose 10\%, pH 6, 0, adaptados por SoaresScott et al. (2003). As placas foram incubadas em câmara úmida, sob luz incandescente, por até 72 horas.

A metodologia para a realização de cruzamentos controlados, germinação das sementes, obtenção de plântulas, plantio e tratos culturais em campo foi a rotineiramente empregada no programa de melhoramento genético do maracujazeiro do IAC (MELETTI et al., 1992; MELETTI e MAIA, 1999; MELETTI et al., 2010).

Os frutos foram analisados quanto às características massa, diâmetros longitudinal e equatorial e número de sementes por fruto em 395 frutos resultantes de polinizações controladas e 3460 frutos de polinização aberta.

As sementes utilizadas nos testes de germinação e de longevidade foram retiradas de frutos maduros, com abscisão natural da planta-mãe. A polpa foi submetida à fermentação para retirada do arilo das sementes, com lavagens sucessivas em água corrente até a remoção total. A secagem das sementes ocorreu em condições ambientais, entre 20 e $25^{\circ} \mathrm{C}$, em sombra, até umidade final de $11 \%$, quando foram acondicionadas em sacos de papel, sendo armazenadas por diferentes períodos de tempo (6,12 e 18 meses), em câmara seca e fria. Um lote de 2000 sementes dos três primeiros acessos cultivados (São Paulo, Rio de Janeiro, EEMAS) foi armazenado e posteriormente utilizado nessas avaliações.

Antes da instalação desses testes, as sementes foram submetidas a um choque térmico, visando à quebra de dormência, incremento na taxa de germinação e uniformização na emergência das plântulas, como já observado para outras espécies de maracujá (Meletti et al., 2002). As sementes foram imersas em água quente, a $40^{\circ} \mathrm{C}$ por 15 minutos, sendo semeadas em seguida.

O teste padrão de germinação (TPG) das sementes seguiu as Regras para Análise de Sementes (Brasil, 1992), após seis, doze e dezoito meses de armazenamento em câmara seca e fria $\left(7^{\circ} \mathrm{C}\right.$ sob $6 \%$ de umidade). As sementes foram separadas em lotes de 100, em cinco repetições, por época de avaliação. Para maior padronização, foram descartadas sementes com tamanho inferior a dois $\mathrm{mm}$ e de coloração clara. A amostragem foi manual, sendo os lotes homogeneizados duas vezes e reduzido pelo método das divisões sucessivas (BRASIL, 1992), para obtenção de uma 
única amostra de trabalho. O substrato utilizado foi rolo de papel, em condições de câmara de germinação com temperatura alternada $20-30{ }^{\circ} \mathrm{C}$. A primeira contagem da taxa de germinação (\%) deu-se aos 14 dias após instalação e a última, aos 28 dias. Os dados foram submetidos à análise estatística pelo Teste de Tukey a $1 \%$ de probabilidade.

A germinação das sementes foi igualmente avaliada em substrato à base de Plantmax ${ }^{\circledR}$ e vermiculita, na proporção $1: 1$, em recipiente plástico. $\mathrm{O}$ teste foi conduzido em telado sob temperatura de 28 a $30^{\circ} \mathrm{C}$, por 30 dias, anotando-se a porcentagem de plântulas emergidas ao final do período.

\section{RESULTADOS E DISCUSSÃO}

\section{a) Características vegetativas}

As plantas apresentaram vigor vegetativo intermediário, com caule cilíndrico, menos robusto que o das espécies comerciais ( $P$. edulis Sims e $P$. alata Curtis), e mais robusto que o de outras espécies nativas, tais como $P$. capsularis L., $P$. foetida L., $P$. misera Kunth e $P$. morifolia Mast., entre outras. Apesar disso, cresceram rapidamente até o arame de sustentação a $2 \mathrm{~m}$ do solo, alcançando-o aos 82 dias após o plantio de primavera e aos 96 dias, quando no plantio de outono, sob as mesmas condições de adubação, segundo MELETTI e MAIA, 1999. O caule levou cerca de seis meses para se lignificar.

Passiflora mucronata, embora tenha seu limite sul de distribuição no litoral norte paulista, mostrou-se tolerante ao frio, condição de Monte Alegre do Sul, ocasião em que diversas passifloráceas paralisaram seu crescimento, florescimento e frutificação. Isso representa vantagem adicional, em localidades de clima ameno. A brotação e produção de folhas foram ininterruptas do final do inverno até o final do outono seguinte.

Observou-se significativa massa vegetativa nas plantas durante nove meses do ano, indicando que se trata de uma espécie apropriada para a formação de cercas vivas. As folhas são simples, inteiras, ovadas a orbiculares e menores $(5,0-10,5 \times 4,0-8,5 \mathrm{~cm})$ que as dos maracujás-amarelos $(P$. edulis). Apresentam um par de nectários próximo ao meio do pecíolo e estípulas ovado-lanceoladas, aristadas, com $1,5-2,5 \times 1,0-1,5 \mathrm{~cm}$. A planta possui folhas bem distribuídas, permitindo suficiente distribuição de luz no interior da planta durante o ano todo.

Embora não tenham sido realizados testes específicos de resistência a pragas e doenças, as plantas de todos os acessos avaliados não apresentaram sintomas de infestação de pragas ou infecções generalizadas, mostrando-se mais longevas que materiais selecionados das espécies comerciais (P. edulis e $P$. alata). Entretanto, as plantas se mostraram sensíveis à deficiência de cálcio, expressa por uma coloração amarela intensa nas folhas que precisa ser bem manejada a fim de manter a alta taxa de florescimento de P. mucronata. Quando o adubo foliar foi utilizado de forma complementar, as folhas apresentaram uma aparência bastante saudável, exuberante e vigorosa. O caráter não decíduo da espécie e o brilho das suas folhas the conferem vistosa folhagem durante o ano todo, destacando seu valor ornamental.

\section{b) Características reprodutivas das plantas}

Todos os acessos avaliados de P. mucronata foram re- presentados por indivíduos bastante produtivos, com elevada quantidade de botões e flores por metro linear (Figura 1). Esta foi a característica de maior destaque da espécie, embora o longo período de florescimento durante o ano tenha sido outro diferencial. A boa distribuição da folhagem deve contribuir para a taxa fotossintética das folhas internas e consequente manutenção de elevado número de botões e flores em toda a cortina produtiva. Passiflora mucronata apresenta uma flor por nó (axila da folha), envolvida por três brácteas (ca. 2 x 1,5cm) verticiladas no botão, dispondo-se em posição ereta na antese. Nos acessos analisados, foi observada emissão de botões florais durante 9-10 meses consecutivos, nas condições climáticas de Monte Alegre do Sul - SP. Os botões e as flores começaram a aparecer em fevereiro, seguindo-se vários florescimentos sucessivos até o final do ano, interrompidos apenas nos dois meses mais chuvosos, dezembro e janeiro. As flores são muito alvas, quase fosforescentes, destacando-se na massa de folhas, num efeito ornamental diferenciado (Figura 2). Com base no número de frutos colhidos, produzidos por polinização aberta e na porcentagem de frutificação observada para este tipo de polinização, estima-se que sejam produzidas cerca de 2000 flores por planta, ao longo do ano, nas condições estudadas.

A antese das flores ocorreu a partir das 18h00min, prolongando-se por toda a noite e início da manhã seguinte. Elas atraem mariposas e morcegos como visitantes noturnos em seu ambiente natural de ocorrência, e sua polinização é mediada por morcegos (SAZIMA e SAZIMA, 1978). Segundo estes autores, a espécie de morcegos mais comum, polinizadores de $P$. mucronata em seu ambiente natural é a Glossophaga soricina (Pallas), que tem ampla distribuição e pode ter atuado como polinizador na área de cultivo estudada. Devido à ausência de frutificação (1997-2003), quando se dispunha de um único acesso (clone), concluiuse que, nas referidas condições, a espécie permaneceu isolada reprodutivamente das demais, possivelmente porque a abertura de suas flores ocorre num horário diferente da maioria das espécies de Passiflora, pelas diferenças de polinizadores e pela expressiva autoincompatibilidade desta espécie.

A planta oferece a possibilidade de utilização diferencial em função da antese noturna de suas flores, já que grande parte das plantas ornamentais é de antese exclusivamente diurna. Flores de cor branca ficam bastante destacadas à noite, podendo ser utilizadas em casas noturnas, restaurantes ou outros estabelecimentos de lazer. Desde o fim do dia, oferecem uma visão prazerosa e uma possibilidade adicional de bem-estar após o dia de trabalho. Entretanto, em seu ambiente natural de ocorrência, a antese se iniciaria apenas de madrugada (01h00min-02h00min), se estendendo até às 07h00min-10h00min (13h00min), em função das condições climáticas (SAZIMA e SAZIMA, 1978).

A viabilidade polínica permaneceu elevada por muitas horas, desde a antese até a manhã seguinte, alcançando valores da ordem de 75,8\%, em 2009 (Tabela 1). Foram analisadas 72 flores recém-abertas, de 2004 a 2009, período em que a análise de um total representativo de 21.600 grãos de pólen indicou viabilidade polínica elevada e crescente. Nos testes de germinação de tubo polínico, concomitantes, para se avaliar a capacidade de fecundação dos grãos de 
pólen, observou-se emissão de tubo polínico até quase 12 horas após a antese, possibilitando a fecundação da flor durante um longo período.

A produção de frutos foi abundante, tanto resultante de polinização cruzada entre os diferentes acessos (Tabela 2), quanto por ação dos polinizadores naturais, com colheitas de maio a janeiro, irregularmente distribuídas.

É importante destacar que para a frutificação de $P$. $m u$ cronata é fundamental a presença de mais do que um indivíduo, de genótipos diferentes, porque existe expressiva autoincompatibilidade na espécie. A polinização cruzada foi a mais eficiente, alcançando, em média, mais que o dobro da porcentagem de frutificação em relação à polinização aberta (Tabela 2). Com base nos acessos analisados, deduz-se que a espécie não aceita autofecundação, pois $98 \%$ das tentativas não foram bem sucedidas. Isso confirma observações anteriores, quando se dispunha de um único clone, que na havia a formação de frutos em $P$. mucronata. O fenômeno da autoincompatibilidade é complexo, podendo depender da ação de mais do que um gene, sendo que em determinadas combinações genéticas podem existir diferenças de compatibilidade, inclusive, entre cruzamentos recíprocos, caso a planta atue como mãe ou como o pai (SUASSUNA et al., 2003).

O sucesso na frutificação de $P$. mucronata com polinização cruzada, manual, nas condições avaliadas foi em média de 40\%, enquanto em condições naturais, Sazima e Sazima (1978) obtiveram 65\%, em 13 cruzamentos avaliados. Entretanto, constataram-se diferenças entre os anos, mas especialmente associadas ao tamanho das amostras (Tabela 2). Verificou-se a possibilidade de hibridação interespecífica de P. mucronata, através de polinização manual. O sucesso da frutificação pela hibridação interespecífica controlada em $P$. mucronata chegou a ser maior do que a polinização cruzada, entretanto com menor produção de sementes viáveis (Tabela 2). A hibridação interespecífica ocorreu em P. mucronata, em todos os acessos avaliados, sendo positiva com $P$. amethystina J.C.Mickan, P. coccinea Aubl., P. edulis, P. malacophylla Mast. e P. serratodigitata L.. Não se obteve sucesso na hibridação apenas com $P$. cincinnata Mast. (duas tentativas) e $P$. caerulea (uma tentativa), mas este resultado não é conclusivo, em função do baixo número de tentativas.

\section{c) Frutos e Sementes:}

Os frutos são ovoides e pequenos quando comparados ao padrão comercial atualmente vigente no mercado. Em 395 frutos, obtidos em polinizações controladas, em média o tamanho foi de $4,5 \times 2,7 \mathrm{~cm}$, de diâmetro longitudinal e equatorial, respectivamente (variando de 2,1-6,6 x 1,2-4,6cm), com massa média de 14,3g, (variando de 1,6-38,6g). Apresentaram média de 136 sementes maduras por fruto (com um máximo de 321 sementes), tendo sido observados frutos vazios, sem nenhuma semente madura (abortadas). Quando considerados os frutos resultantes de polinização aberta, suas características foram bastante semelhantes, tanto em relação ao tamanho dos frutos, massa e número de sementes, mesmo tendo sido amostrado um número bem maior de frutos (de 1105 a 3340 frutos, conforme a característica). Isso demonstra que, diferentemente dos maracujás comerciais das espécies $P$. edulis e $P$. alata, a polinização manual intraespecífica não confere incremento significativo nesses parâmetros de qualidade, o que é altamente notório e desejável nas espécies citadas.

A casca apresentou-se verde-opaco ou amarelo-canário, com menos de $3 \mathrm{~mm}$ de espessura, polpa pouco suculenta com o arilo aderido às sementes, sem aroma pronunciado. A polpa não é ácida, embora menos doce em relação à polpa dos maracujás roxos $(P$. edulis) e dos maracujás doces (Passiflora alata), apresentando sabor agradável. As sementes são achatadas, de coloração marrom-enegrecida.

Os frutos gerados pelos cruzamentos manuais entre plantas de diferentes acessos foram bastante uniformes (Figura 3), sendo que suas características externas (cor e forma) não diferiram substancialmente entre si. Novamente, isto diferencia este maracujazeiro dos comerciais do mercado ( $P$. edulis e $P$. alata), cujos frutos apresentam elevada variabilidade em tamanho, formato e coloração (OLIVEIRA et al., 1988; MELETTI et al., 1992).

Em condições padrão para germinação (TPG), observou-se que a espécie apresentou dormência nas sementes recém-colhidas (Tabela 3), tal como ocorrido em outras passifloras nativas ainda não submetidas a nenhum processo de domesticação (MELETTI et al., 2002). Observou-se uma pequena porcentagem de germinação, inferior a $10 \%$, ao final do período prescrito. No entanto, após armazenamento, as sementes mantidas sob refrigeração por seis meses apresentaram uma germinação bastante ampliada, na ordem de 72,8\%, índice superior à maioria das espécies de passifloras não domesticadas. Após um ano de armazenamento, observou-se um índice $67,1 \%$ de germinação, igualmente elevado para espécie não cultivada e após 18 meses de armazenamento, ainda se observou um índice de 29\%, maior que o de muitas outras passifloráceas em igual condição, mesmo quando submetidas a choque térmico para quebra de dormência, como $P$. nitida Bonpl. ex Kunth., que, mesmo com tratamento térmico adicional para quebra de dormência, não consegue superá-la. Isso comprovou que o armazenamento em câmara seca e fria associado ao choque térmico foi capaz de ampliar a germinação (\%) das sementes de $P$. mucronata, que atingiu índices bastante interessantes para uma espécie não domesticada, especialmente nas sementes de seis meses a um ano de idade (Tabela 3).

Nessas condições, observou-se uma ampliação na porcentagem de germinação e de emergência das sementes de P. mucronata. A germinação rápida e uniforme das sementes, seguida por pronta emergência das plântulas são características altamente desejáveis na formação de mudas, porque facilitam o manejo no viveiro. Através do melhoramento, selecionam-se plantas com maior capacidade de deixar descendentes, que se reproduzem rapidamente. No caso de espécies ainda não domesticadas como esta, é esperado o comportamento inverso: germinação de sementes distribuída ao longo do tempo, como forma de garantir a preservação da espécie a partir de uma pequena porção das sementes, que germinam quando as condições ambientais estão favoráveis ao seu desenvolvimento (MELETTI et al., 2002).

As sementes recém-colhidas superaram parcialmente sua dormência natural por ação do choque térmico, uma vez que a germinação inicial (\%) sempre foi maior que zero (Tabela 3). Sementes não submetidas a nenhum tratamento 
térmico no momento da instalação do TPG apresentaram porcentagem de germinação de zero a um máximo de $15 \%$, independentemente do período de armazenamento subsequente, confirmando que, para $P$. mucronata, é interessante a associação destes dois métodos de superação de dormência a fim de que suas sementes germinem em níveis aceitáveis comercialmente.

Assim como para as espécies Passiflora edulis, P. cincinnata e $P$. setacea DC, já testadas anteriormente por MELETTI et al. (2002), observou-se efeito positivo e sinérgico dos dois métodos associados (armazenamento e choque térmico), quando então se obteve adequada germinação (\%) de sementes de P. mucronata.

Além da facilidade de execução e baixo custo, o tratamento térmico permitiu elevar a porcentagem de germinação e concentrar a emergência das plântulas num curto espaço de tempo, uniformizando os lotes de mudas. Esses resultados assumem maior importância prática para a propagação comercial, em que essas características são altamente desejáveis.

Sementes armazenadas por tempo superior a um ano apresentaram uma taxa de germinação significativamente inferior, indicando perda de viabilidade progressiva após este período. Em todos os testes de avaliação, aos 14 dias, a taxa de germinação foi bem inferior à porcentagem final obtida (28 dias), indicando que estas sementes germinam de forma desuniforme e lenta, necessitando de um tratamento para superação de dormência. Observou-se longo período de embebição, associado a uma pequena velocidade de desenvolvimento, embora as plântulas resultantes tenham apresentado taxa superior a $90 \%$ de plântulas normais.

Quanto à emergência em substrato, dentro de viveiro, observou-se um comportamento similar à germinação pelo TPG, sendo que após seis meses de armazenamento foi obtida a maior taxa de emergência $(68,8 \%)$, seguida pelas sementes com um ano de armazenamento $(45,5 \%)$ e depois pelas armazenadas por 18 meses, que atingiram $22 \%$ de emergência em viveiro, após 30 dias de avaliação.

Pelos resultados obtidos, observou-se que as sementes de $P$. mucronata têm comportamento ortodoxo, com cerca de um ano de longevidade quando armazenadas em condições de câmara seca e fria. Este fato aponta para a possibilidade de conservação em médio prazo, o que não foi testado em outras passifloras ainda não domesticadas.

O maior conhecimento da espécie indicou que ela possui atributos significativos para fins ornamentais. A intensidade de florescimento e o amplo período em que ele ocorre representam vantagens para a comercialização da espécie, quando comparada a outras plantas, inclusive outras espécies de Passiflora, especialmente aquelas que apresentam período restrito de florescimento. Ainda, embora a polpa seja pouco sucosa, possui sabor agradável, e os saborosos frutos são uma recompensa adicional ao caráter ornamental da espécie. As plantas apresentam grande longevidade e aparente resistência às pragas e doenças mais comuns aos maracujazeiros. A possibilidade de armazenamento das sementes permite a formação de lotes para a produção de mudas em diferentes ocasiões.

\section{CONCLUSÕES}

Os acessos de Passiflora mucronata estudados apresentaram elevado potencial ornamental, sendo uma alternativa adicional no grupo das plantas trepadeiras indicadas para cercas vivas ou caramanchões. Possuem longo período de florescimento, flores alvas e fosforescentes, com antese noturna, resistência ao frio e vigor vegetativo moderado nas condições avaliadas.

O comportamento germinativo ortodoxo observado nos acessos desta espécie permite a formação de lotes comerciais de sementes para produtores. A longevidade das sementes é maior que a da maioria das passifloráceas já estudadas, o que permite formação de mudas por um período de um ano após a colheita.

\section{AGRADECIMENTOS}

Agradecemos a Deise Maria Pagan Manginelli e Maria Aparecida Resende Braga Azevedo, do Polo Regional de Desenvolvimento Tecnológico dos Agronegócios do Leste Paulista, pela digitação dos dados, execução de cruzamentos controlados e manutenção da identidade dos cruzamentos até a colheita, e à bióloga Isabela Porto Renó, pelas medições de frutos e digitação de dados.

\section{REFERÊNCIAS}

ALEXANDER, M.P. A versatile stain for pollen, fungi, yeast and bacteria. Stain Technology, Estocolmo, v. 55, n. 1, p. 13-18, 1980.

BERNACCI, L.C.; Vitta, F.A. \& Bakker, Y.V. Passifloraceae. In: Wanderley, M.G.L.; Shepherd, G.J.; Giulietti, A.M.; Melhem, T.S. (Ed.). Flora Fanerogâmica do Estado de São Paulo. São Paulo: RiMa/FAPESP, 2003, v. 3, p. 247274.

BERNACCI, L.C.; MELETTI, L.M.M.; SCOTT, M.D.S.; PASSOS, I.R.S. \& JUNQUEIRA, N.T.V. Espécies de maracujá: caracterização e conservação da biodiversidade. In Faleiro, F.G.; Junqueira, N.T.V.; Braga, M.F. (Org.). Maracujá: germoplasma e melhoramento genético. Planaltina - DF: EMBRAPA Cerrados, 2005, p. 559-586.

BRASIL, Ministério da Agricultura e da Reforma Agrária. Regras para análise de sementes. Brasília: SNDA/ DNDV/CLAV, 1992. 365p.

CERVI, A.C.; MILWARD-DE-AZEVEDO, M.A.; BERNACCI, L.C. Passifloraceae. In Forzza, R.F. et al. (eds.) Catálogo de plantas e fungos do Brasil. Rio de Janeiro: Jardim Botânico do Rio de Janeiro. v. 2, p.1432-1436, 2010.

CIIAGRO (Centro integrado de informações agrometeorológicas). Ciiagro Online: resenha agrometeorológica. Disponível em: http://www.ciiagro.sp.gov.br/ciiagroonline/. Acesso em 09/12/2010. 
DAULTA, B.S.; CHAUHAN, K.S. Pollination and in vitro pollen germination studies in grapes (Vitis vinifera L.) Haryana Journal of Horticultural, Haryana, v. 16, n. 3-4, p. 204-208, 1987.

INGLEZ-DE-SOUZA, J.S.; MELETTI, L.M.M. Maracujá: espécies, variedades, cultivo. Piracicaba: FEALQ, 1997. 179p.

MELETTI, L.M.M.; MAIA, M.L. Maracujá: produção e comercialização. Campinas: Instituto Agronômico, 1999. 62 p. (Boletim Técnico, 181)

MELETTI, L.M.M.; OLIVEIRA, J.C.; RUGGIERO, C. Maracujá. FUNEP: Jaboticabal. 2010. 55p. ilustr. (Série Frutas Nativas, 6)

MELETTI, L.M.M.; SOARES-SCOTT, M.D.; PINTOMAGLIO, C.A.F; MARTINS, F.P. Caracterização de germoplasma de maracujazeiro (Passiflora sp). Revista Brasileira de Fruticultura, Jaboticabal, v. 14, n. 2, p.157-162, 1992.

MELETTI, L.M.M.; FURLANI, P.R.; ÁlVARES, V.; SOARES-SCOTT, M.D.; BERNACCI, L.C.; AZEVEDO FILHO, J.A. Novas tecnologias melhoram a produção de mudas de maracujá. O Agronômico, Campinas, v. 54, n. 1, p. 30-33, 2002.
MELLO FILHO, L.E. Plantas ornamentais em paisagismo. In: Encontro Nacional sobre Floricultura e Plantas Ornamentais, 1986, Org.Kampf,A.N. 1986. Anais. p.55-63.

OLIVEIRA, J.C.; FERREIRA, F.R.; RUGGIERO, C.; NAKAMURA, K. Caracterização e avaliação de germoplasma de Passiflora edulis. In: CONGRESSO BRASILEIRO FRUTICULTURA, 9, 1988, Campinas-SP. Anais. Campinas: Sociedade Brasileira Fruticultura, 1988. v. 2, p. 591-596.

ROLIM, G.S.; SENTELHAS, P.C. BHnorm V5.0: balanço hídrico normal de Monte Alegre do Sul (SP). 1999. Disponível em: http://www.leb.esalq.usp.br/bhbrasil/Saopaulo/ MonteAlegreSul.xls. Acesso em 09/12/2010.

SAZIMA, M.; SAZIMA, I. Bat pollination of the passion flower, Passiflora mucronata, in Southeastern Brazil. Biotropica, Hoboken, v. 10, n. 2, p. 100-109, 1978.

SOARESSCOTT, M.D.; MELETTI, L.M.M.; RECCO-PIMENTEL, S.M. Meiotic behaviour and pollen fertility in sexual and somatic hybrids of Passiflora species. Caryologia, Florença, v. 56, n. 1, p. 129-138, 2003.

SUASSUNA, T.M.F.; BRUCKNER, C.H.; CARVALHO, C.R.; BORÉM, A. Self-incompatibility in passionfruit: evidence of gametophytic-sporophytic control. Theoretical and Applied Genetics, Berlim, v. 106, p. 298-302, 2003.

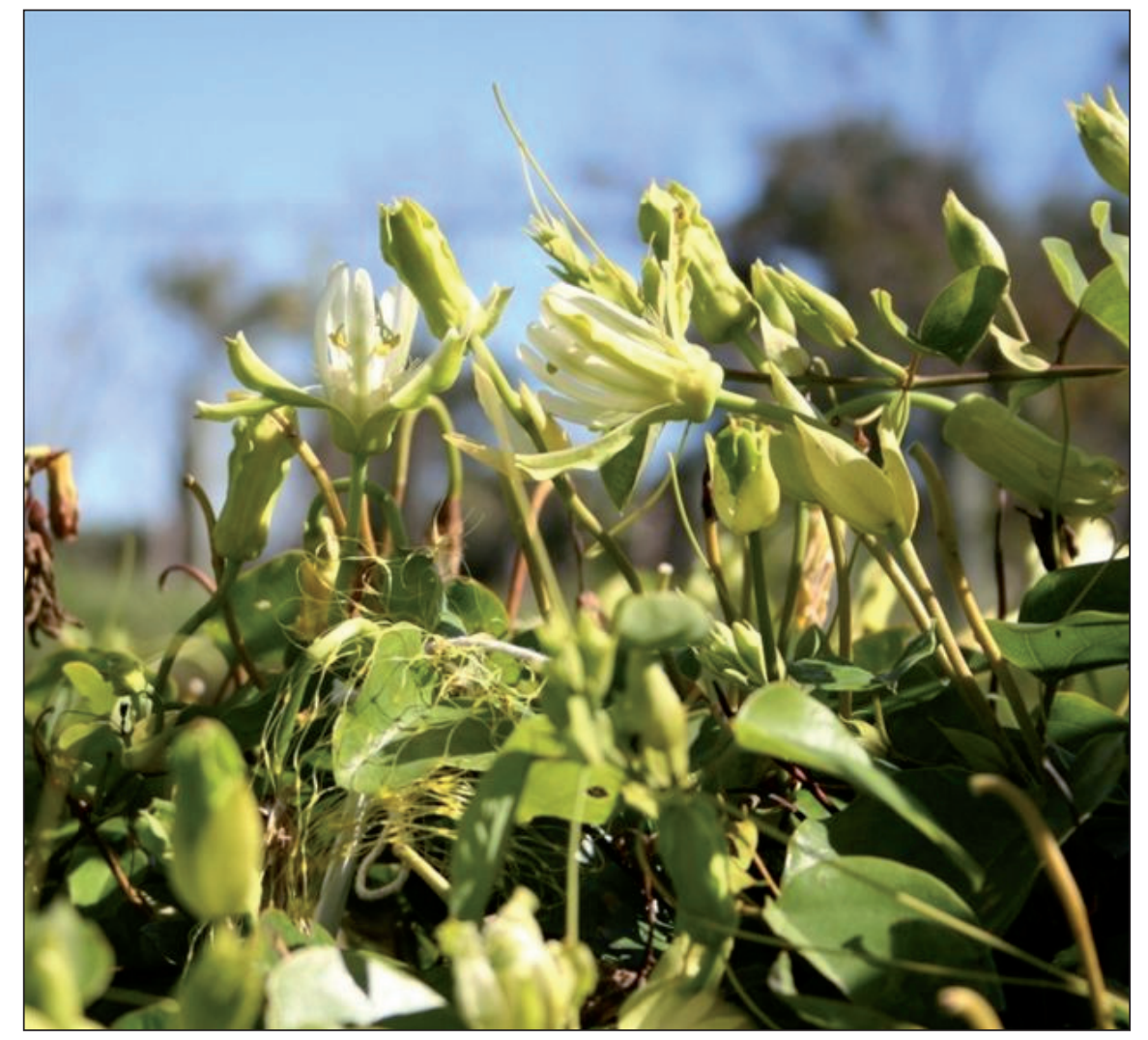

Figura 1. Abundância de flores e botões em Passiflora mucronata Lam. sob cultivo em Monte Alegre do Sul (SP). Figure 1. Abundance of flowers and buttons in Passiflora mucronata Lam., grown at Monte Alegre do Sul (SP). 


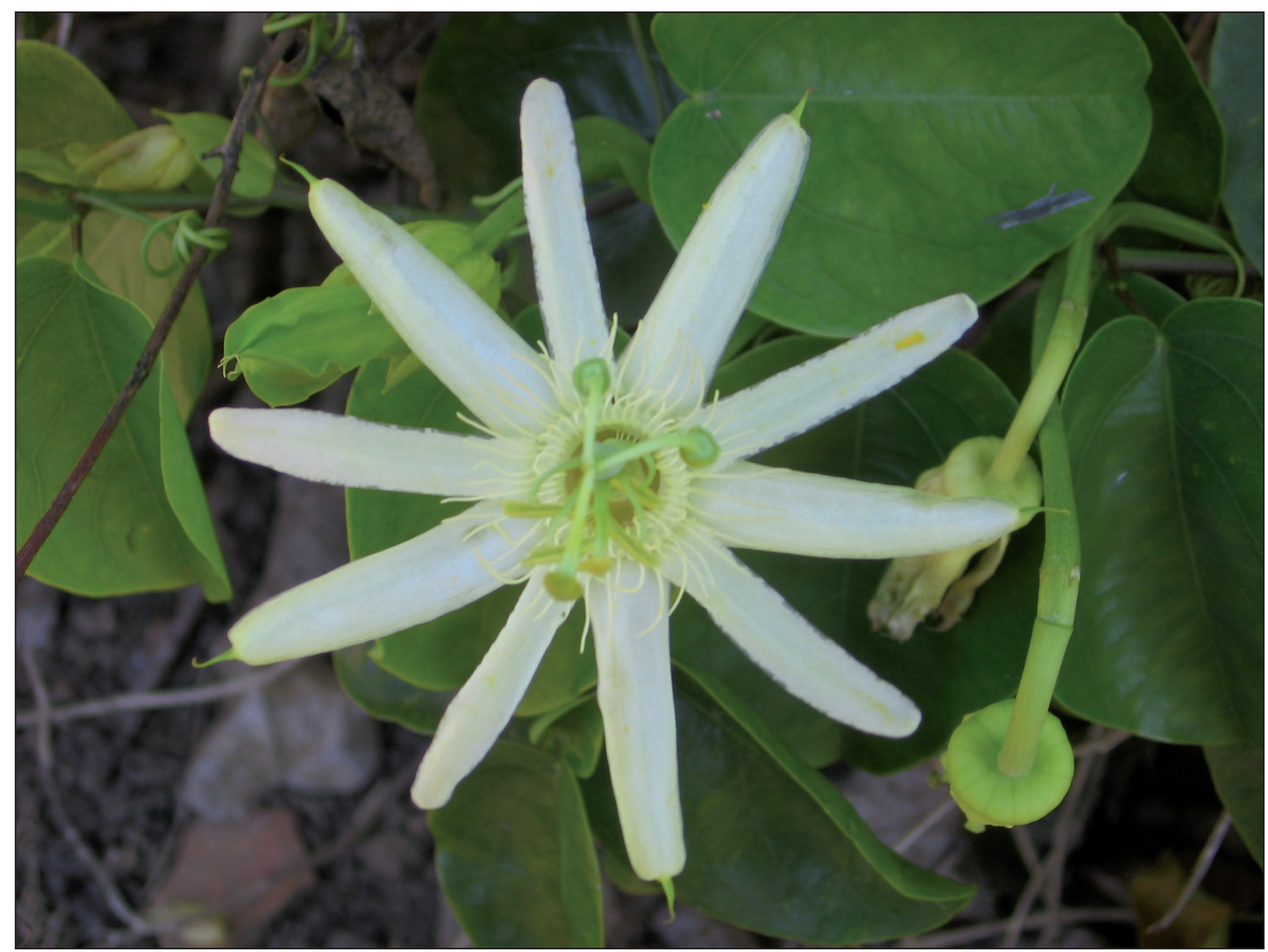

Figura 2. Flor de Passiflora mucronata Lam., destacando-se entre a folhagem, em cultivo em Monte Alegre do Sul (SP). Figure 2. Flower of Passiflora mucronata Lam., standing out among the foliage, grown at Monte Alegre do Sul (SP).

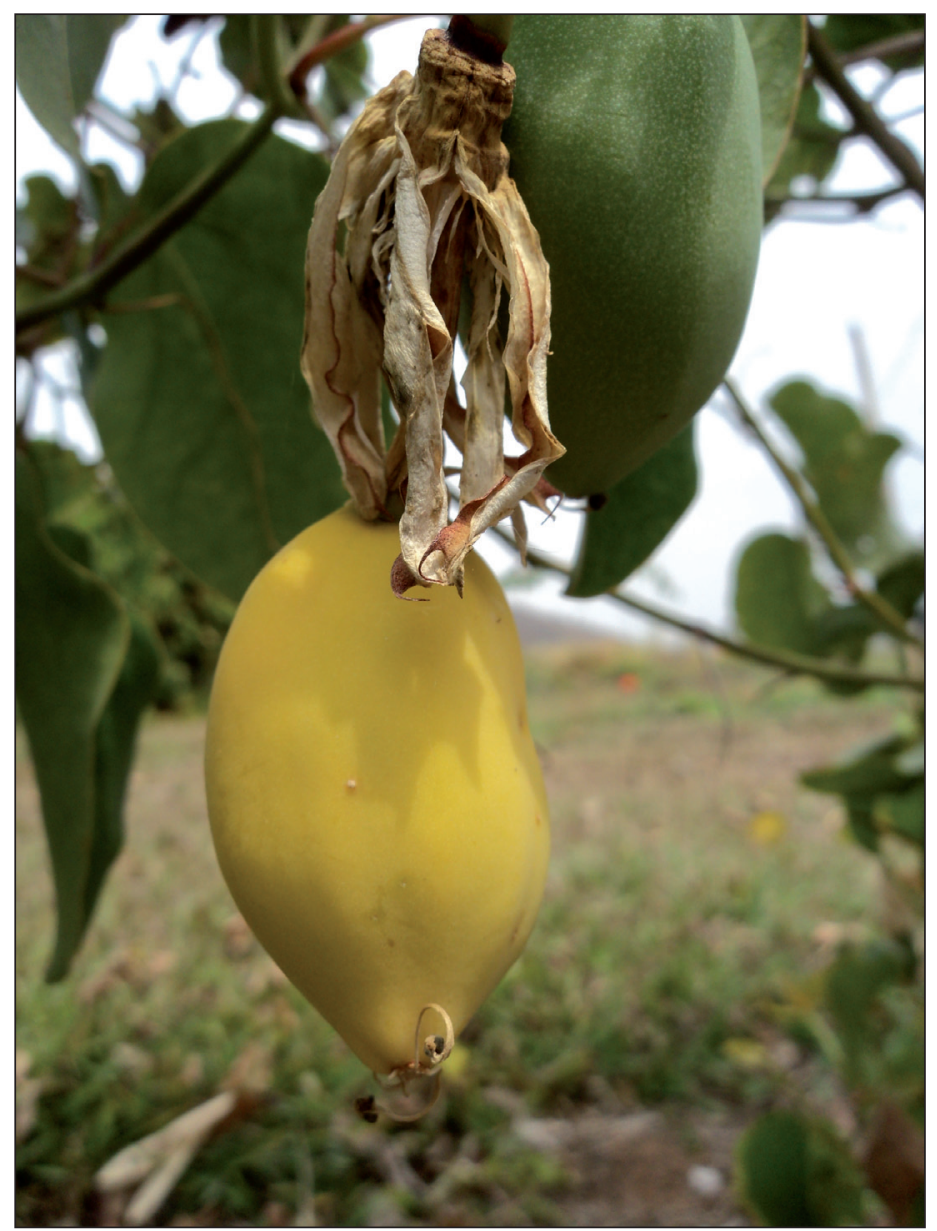

Figura 3. Passiflora mucronata Lam. cultivado em Monte Alegre do Sul (SP), destacando-se os frutos.

Figure 3. Passiflora mucronata Lam. grown at Monte Alegre do Sul (SP), highlighting the fruits. 
Tabela 1. Viabilidade polínica em Passiflora mucronata Lam. Monte Alegre do Sul (SP), 2005-2009.

Table 1. Pollen viability in Passiflora mucronata Lam. Monte Alegre do Sul (SP), 2005-2009.

\begin{tabular}{|c|c|c|c|c|}
\hline & & \multicolumn{3}{|c|}{ Pólen } \\
\hline Ano & Número de flores & Total & Viável & Viabilidade polínica (\%) \\
\hline 2005 & 10 & 3000 & 2100 & 70,0 \\
\hline 2006 & 16 & 4800 & 3336 & 69,5 \\
\hline 2007 & 14 & 4200 & 3003 & 71,5 \\
\hline 2008 & 12 & 3600 & 2664 & 74,0 \\
\hline Total & 20 & 6000 & 4548 & 75,8 \\
\hline
\end{tabular}

Tabela 2. Pegamento e frutificação (\%), massa, diâmetros longitudinal e equatorial dos frutos, número de sementes de Passiflora mucronata Lam., por tipo de polinização, Monte Alegre do Sul (SP), 2004-2010. No número; Ø diâmetro; - não analisado.

Table 2. Early fruiting and fruiting (\%), weight, longitudinal and equatorial diameters of fruits, number of seeds of Passiflora mucronata Lam., by type of pollination Monte Alegre do Sul (SP), 2004-2010. No number; Ø diameter: - not analyzed.

\begin{tabular}{|c|c|c|c|c|c|c|c|c|}
\hline \multirow[b]{2}{*}{ Ano } & \multirow[b]{2}{*}{$\begin{array}{c}\text { Tipo de } \\
\text { polinização }\end{array}$} & \multirow[b]{2}{*}{$\mathbf{N}^{\circ}$} & \multicolumn{2}{|c|}{ Porcentagem (\%) } & \multicolumn{4}{|c|}{ Frutos (Média) } \\
\hline & & & Pegamento & Frutificação & $\begin{array}{l}\varnothing \text { longitudinal } \\
\text { (cm) }\end{array}$ & $\begin{array}{l}\varnothing \text { equatorial } \\
\text { (cm) }\end{array}$ & $\begin{array}{l}\operatorname{massa} \\
(\mathrm{g})\end{array}$ & $\begin{array}{c}\text { Sementes } \\
\text { maduras }\end{array}$ \\
\hline \multirow{2}{*}{2004} & Aberta & 26 & 3,85 & 0 & 0 & 0 & 0 & 0 \\
\hline & Autofecundação & 44 & 0 & 0 & 0 & 0 & 0 & 0 \\
\hline \multirow{3}{*}{2005} & Aberta & 32 & 0 & 0 & 0 & 0 & 0 & 0 \\
\hline & Cruzada & 47 & 12,77 & 10,64 & - & - & - & - \\
\hline & Autofecundação & 107 & 0,93 & 0 & 0 & 0 & 0 & 0 \\
\hline \multirow{3}{*}{2006} & Aberta & 14 & 7,14 & 0 & 0 & 0 & 0 & 0 \\
\hline & Cruzada & 1 & 100 & 100 & - & - & - & - \\
\hline & Autofecundação & 11 & 0 & 0 & 0 & 0 & 0 & 0 \\
\hline \multirow{3}{*}{2007} & Aberta & 4 & 0 & 0 & 0 & 0 & 0 & 0 \\
\hline & Cruzada & 32 & 28,13 & 15,63 & 4,13 & 2,66 & 11,68 & 90,60 \\
\hline & Autofecundação & 41 & 12,20 & 2,44 & 5,05 & 4,61 & - & 0 \\
\hline \multirow{3}{*}{2008} & Aberta & 44 & 25,00 & 13,64 & 3,61 & 2,32 & 11,32 & 111,33 \\
\hline & Cruzada & 125 & 37,6 & 20,8 & 4,85 & 2,53 & 8,82 & 90,88 \\
\hline & Autofecundação & 20 & 0 & 0 & 0 & 0 & 0 & 0 \\
\hline \multirow{4}{*}{2009} & Aberta & 70 & 35,71 & 27,14 & 4,38 & 2,58 & 13,99 & 95,51 \\
\hline & Cruzada & 783 & 40,87 & 29,50 & 4,58 & 2,77 & 15,76 & 142,77 \\
\hline & Autofecundação & 365 & 1,37 & 0,27 & 5,15 & 2,88 & 19,50 & 158,00 \\
\hline & Interespecífica & 13 & 46,15 & 38,46 & 4,95 & 2,45 & 11,76 & 88,20 \\
\hline \multirow{3}{*}{2010} & Aberta & 1 & 0 & 0 & 0 & 0 & 0 & 0 \\
\hline & Cruzada & 316 & 43,99 & 33,23 & 4,49 & 2,65 & 13,30 & 150,39 \\
\hline & Autofecundação & 142 & 2,11 & 2,11 & 3,86 & 2,17 & 9,73 & 145,33 \\
\hline \multirow{3}{*}{ Média } & Aberta & 187 & 21,39 & 13,37 & 4,19 & 2,52 & 13,35 & 99,31 \\
\hline & Cruzada & 1304 & 40,03 & 28,60 & 4,49 & 2,67 & 14,28 & 138,30 \\
\hline & Autofecundação & 733 & 2,05 & 0,68 & 4,35 & 2,80 & 12,18 & 118,80 \\
\hline
\end{tabular}


Tabela 3. Germinação de sementes (\%) de Passiflora mucronata Lam. submetidas a três períodos de armazenamento, em condições de câmara fria e seca $\left(7^{\circ} \mathrm{C}\right.$ e $6 \%$ de umidade), com choque térmico associado, Campinas, 2008.

Table 3. Seed germination (\%) of Passiflora mucronata Lam. submitted to three periods of storage under conditions of cold and dry ( $7^{\circ} \mathrm{C}$ and $6 \%$ moisture), more thermal shock, Campinas, 2008.

\begin{tabular}{|l|c|c|}
\hline & \multicolumn{2}{|c|}{ \% germinação } \\
\hline \multicolumn{1}{|c|}{ Período armazenamento } & $\mathbf{1 4}$ dias & $\mathbf{2 8}$ dias \\
\hline Recém-colhidas & $3,2 \mathrm{c}$ & $8,4 \mathrm{c}$ \\
\hline 6 meses & $33,5 \mathrm{a}$ & $72,8 \mathrm{a}$ \\
\hline 12 meses & $23,7 \mathrm{ab}$ & $67,1 \mathrm{a}$ \\
\hline 18 meses & $12,8 \mathrm{~b}$ & $25,8 \mathrm{~b}$ \\
\hline
\end{tabular}

